\title{
Dynamics of Shifting Cultivation Landscapes in Northern Lao PDR Between 2000 and 2009 Based on an Analysis of MODIS Time Series and Landsat Images
}

\author{
Kaspar Hurni - Cornelia Hett - Andreas Heinimann • \\ Peter Messerli • Urs Wiesmann
}

Published online: 8 December 2012

(C) Springer Science+Business Media New York 2012

\begin{abstract}
The rotational nature of shifting cultivation poses several challenges to its detection by remote sensing. Consequently, there is a lack of spatial data on the dynamics of shifting cultivation landscapes on a regional, i.e. subnational, or national level. We present an approach based on a time series of Landsat and MODIS data and landscape metrics to delineate the dynamics of shifting cultivation landscapes. Our results reveal that shifting cultivation is a land use system still widely and dynamically utilized in northern Laos. While there is an overall reduction in the areas dominated by shifting cultivation, some regions also show an expansion. A review of relevant reports and articles indicates that policies tend to lead to a reduction while market forces can result in both expansion and reduction. For a better understanding of the different factors affecting shifting cultivation landscapes in Laos, further research should focus on spatially explicit analyses.
\end{abstract}

Keywords Shifting cultivation $\cdot$ MODIS $\cdot$ Landsat · landscape metrics $\cdot$ Lao PDR

K. Hurni $(\bowtie) \cdot$ C. Hett $\cdot$ A. Heinimann $\cdot$ P. Messerli $\cdot$

U. Wiesmann

Swiss National Centre of Competence in Research (NCCR) North-

South, Centre for Development and Environment (CDE), Institute

of Geography, University of Bern, Hallerstrasse 10,

3012 Berne, Switzerland

e-mail: kaspar.hurni@cde.unibe.ch

C. Hett

e-mail: cornelia.hett@cde.unibe.ch

A. Heinimann

e-mail: andreas.heinimann@cde.unibe.ch

P. Messerli

e-mail: peter.messerli@cde.unibe.ch

U. Wiesmann

e-mail: urs.wiesmann@cde.unibe.ch

\section{Introduction}

In Montane Mainland Southeast Asia (MMSEA), shifting cultivation has been the dominant land use practice for centuries, and today remains an important subsistence agriculture system (de Rouw et al. 2005; Inoue et al. 2010, 2007; Mertz et al. 2009). In the uplands of northern Lao PDR (hereafter Laos), shifting cultivation has remained the predominant land use type (Delang 2007; Ducourtieux et al. 2005; Roder et al. 1997; Seidenberg et al. 2003). Since the mid-nineties, this traditional upland agriculture system has undergone dramatic transformations (de Rouw et al. 2005; Ducourtieux 2005; Ducourtieux et al. 2005; World Bank 2008). Population pressure, in combination with economic and political factors, is mainly responsible for these changes. Increased exposure to the neighboring economies of China, Thailand and Vietnam through trade relations and transportation linkages has provided farmers with new opportunities. In addition, national policies blaming shifting cultivation for deforestation encourage its transformation into a more intensive, specialized agricultural production system (Padoch et al. 2007; Roder et al. 1997; Seidenberg et al. 2003; World Bank 2008).

Various case studies in northern Laos reveal that the transformation of traditional shifting cultivation, and especially the speed of this change, has had important consequences for environmental service provision and rural livelihoods (de Rouw et al. 2005; Padoch et al. 2007; Roder et al. 1997; Watanabe et al. 2004). Despite the significance of these changes, reliable information on the extent and the dynamics of change in shifting cultivation landscapes, particularly on a regional scale, remains scarce (Fox et al. 2009; Padoch et al. 2007). Region-wide data is either derived from approximations based on population estimates or from the analysis of aerial photographs (Schmidt-Vogt et al. 2009). However, these appraisals date from the early nineties and show large variations in their 
estimations of the area under shifting cultivation (Mertz et al. 2009; Schmidt-Vogt et al. 2009). The most recent estimate of shifting cultivation landscapes in Laos is provided by Messerli et al. (2009), who delineated the area under shifting cultivation and other types of landscapes from 2002 land cover data by utilizing a moving window approach. While this approach is considered to provide a credible estimate of the extent of the shifting cultivation landscapes, it relies on the availability of national land cover inventories. Often these inventories are carried out only at ten-year intervals and are therefore significantly limited in the frequency of data updates (Mertz et al. 2009). The inclusion of time series information and change detection has been recommended in order to reveal the changes in landscapes dominated by shifting cultivation (Mertz et al. 2009).

This paper presents an approach to addressing this information gap through the use of 10 years of MODIS time series data along with Landsat images, which allows for the delineation of those areas where shifting cultivation prevails. We used the Landsat images to identify land cover dynamics and the MODIS time series data to map them for the whole of northern Laos. Shifting cultivation landscapes show a specific spatio-temporal combination of land cover dynamics. In the MODIS classification, we assessed these characteristics using landscape metrics. Our results revealed not only those landscapes in northern Laos where shifting cultivation dominates but also their dynamics at the provincial to national scale.

\section{Description of the Study Site}

Much of the land area of Laos is mountainous, particularly in the northern uplands, which are characterized by steep slopes and narrow river valleys (see Fig. 1). In flat valley bottoms, paddy fields of varying lengths but only a couple of meters in width often occur. On the hillsides, a land cover mosaic of freshly cleared agricultural plots and different stages of fallow land cover can be observed. These hills are used predominantly for shifting cultivation (Hett et al. 2011; Roder et al. 1997). Various case studies have reported that in northern Laos, especially in the provinces of Luang Namtha, Oudomxay, and Luang Prabang, shifting cultivation is still widespread (Inoue et al. 2010, 2007; Leek 2007; Linquist et al. 2007; Roder 2001; Saito et al. 2006; Yamamoto et al. 2009; Yokoyama 2004)

A good road network connects provincial and most district capitals in northern Laos. However, away from these major transport networks accessibility, in terms of practicable transportation, decreases and travel time to these centers thereby increases. Consequently, changes from and to the shifting cultivation land use practice primarily take place along the major transport routes and the border regions with the introduction of a variety of cash crops and agricultural plantations (Alton et al. 2005; Cramb et al. 2009; Ducourtieux et al. 2006; Fox et al. 2009; Padoch et al. 2007).

Our study area was limited to northern Laos and although our methodology would have allowed an assessment of the whole country, the multiple processing steps and the additional amount of data required for this led us to focus on this region only. This substantially reduced the workload but still allowed us to include the most important shifting cultivation regions in Laos (Delang 2007; Ducourtieux et al. 2005; Roder et al. 1997; Seidenberg et al. 2003).
Fig. 1 Lao PDR, a landlocked country in Southeast Asia between Cambodia, China, Myanmar, Thailand, and Vietnam. The study region covers the area of northern Laos

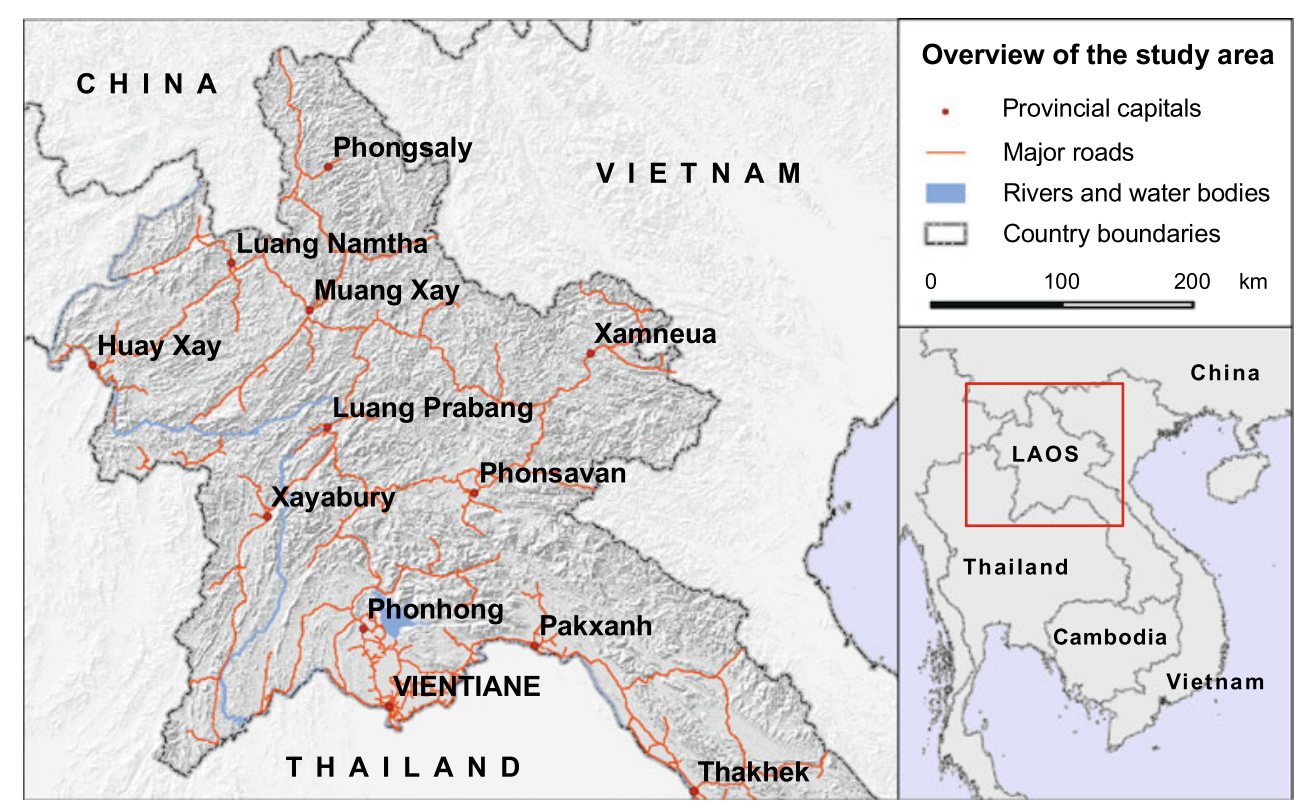




\section{Approach}

The rotational nature of shifting cultivation has implications for assessing the area under this land use. Newly cleared agricultural plots, as well as the different stages of fallow land (plots cultivated in previous years and since left to natural regrowth), need to be taken into consideration. Attempts to map these different stages of forest re-growth using medium resolution images (e.g. Landsat) can suffer inaccuracies in mountainous areas due to terrain shadows (Dorren et al. 2003). It is thus impossible to assess the area under shifting cultivation using images taken at only a single point in time. While different stages of forest re-growth cannot be distinguished in the images, it is still possible to separate newly cleared agricultural plots from vegetated land cover. Thus using time series images, the spatio-temporal dynamics of these plots allow for an assessment of shifting cultivation landscapes (Heinimann 2006; Schmidt-Vogt et al. 2009).

Still, there are constraints when working with a time series of Landsat images on a regional or national level since data availability is often highly limited due to frequent cloud cover and haze. As a result, consistent and free of charge Landsat time series images at these levels are not yet available. Up to now, studies focusing on shifting cultivation in Laos are either spatially limited, as in Inoue et al. (2007) or Yamamoto et al. (2009), or show a temporal limitation in comparing only two time steps, as in Heinimann (2006).

In order to overcome these constraints, we present an approach using yearly Landsat images, time series of MODIS data, and landscape metrics. The medium spatial and temporal resolution of the Landsat data allowed the accurate mapping of the land cover change trajectories for the extent of one Landsat scene over 10 years. Mertens and Lambin (2000) define land cover change trajectories as successions of land cover types over more than two observations. Due to the limitations of the Landsat data, this approach does not provide consistent coverage. In Fig. 2, 1c, the data gaps can be seen as blank areas between the change trajectories (represented by different colors).

MODIS time series data has the potential to provide spatially continuous data. While the low spatial resolution provided by MODIS is less than that of Landsat, the high temporal resolution of MODIS data allows for the elimination of most of the data gaps caused by cloud cover and haze. In addition, each land cover change trajectory represents a specific vegetation dynamic over time. Having data
Fig. 2 Three-step approach to assessing the dynamics of shifting cultivation landscapes in northern Laos using a postclassification comparison of Landsat images, the classification of MODIS time series data and landscape metrics. See Figs. 4 and 6 for a legend to the maps

\section{1}

(a)

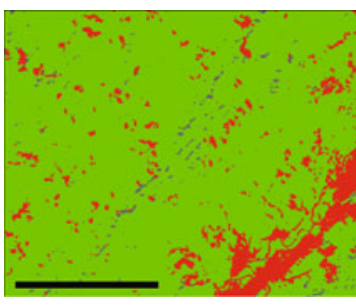

(b)

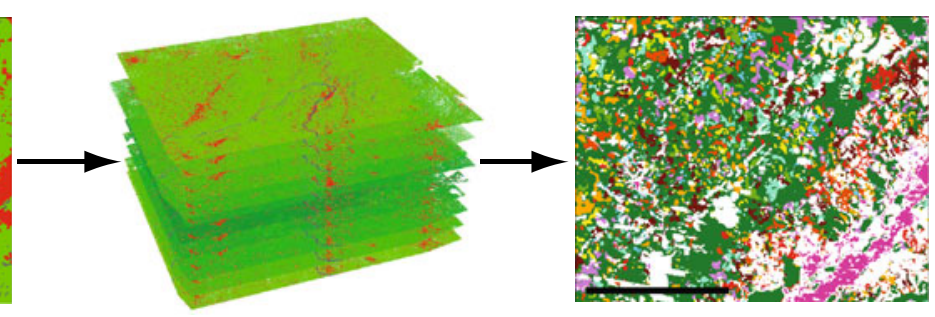

(a)

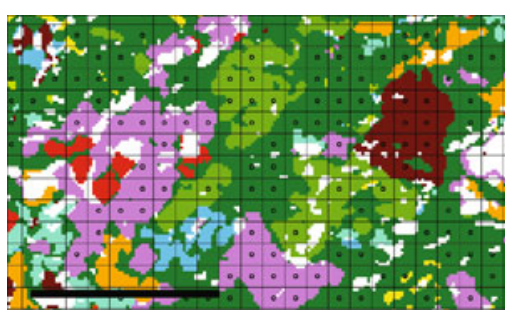

3

(a)

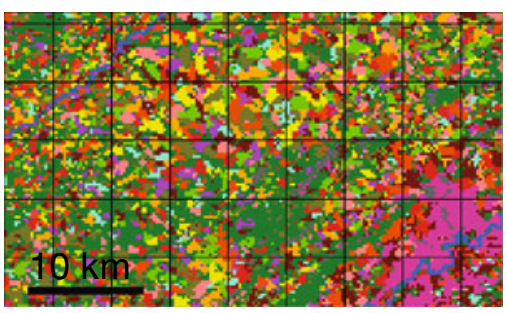

(b)

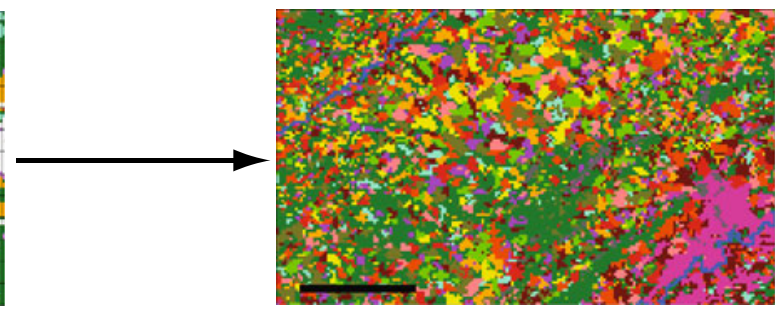

(b)

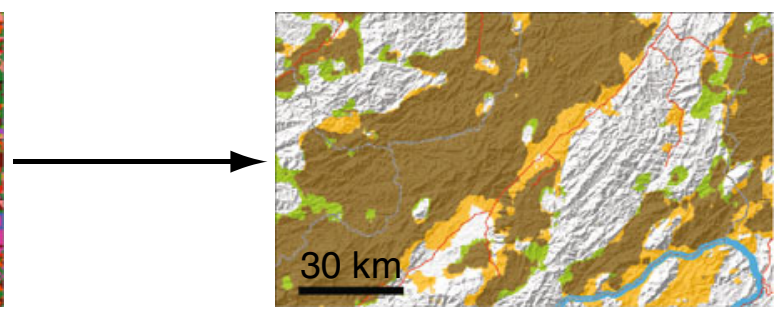


with a high temporal resolution is thus beneficial for the detection of these trajectories.

Since the MODIS time series data could not be classified without prior knowledge of the major land cover and its dynamics, we used the information on land cover change trajectories from the Landsat analysis to derive training samples for the classification of the MODIS time series. This allowed us to map the prevailing land cover change trajectories for northern Laos. Using landscape metrics, we then delineated the landscapes dominated by shifting cultivation. As illustrated in Fig. 2, the approach has three main steps:

1. Assessment of the land cover change trajectories occurring: We applied a binary classification of "medium to high biomass density" (HB) and "low to no biomass density" (NB) to each of a time series of Landsat images at yearly intervals. Post-classification comparison revealed the type, location, and incidence of stable $\mathrm{HB}$ and NB land cover, and of the land cover change trajectories. An analysis of the sequence of the two classes ( $\mathrm{HB}$ and $\mathrm{NB}$ ) over 10 years allowed us to relate a land cover change trajectory to a certain process, such as shifting cultivation (Heinimann 2006; Mertens and Lambin 2000; Yamamoto et al. 2009).

2. Identification of the prevailing land cover change trajectories for the whole of northern Laos:

MODIS time series data covering the area of northern Laos was classified. Training areas were derived from the Landsat post-classification comparison. A specific land cover change trajectory was selected as training area if it covered more than $75 \%$ of a MODIS pixel and if these MODIS pixels, representing a specific land cover change trajectory, occurred in a certain number.

3. Detection and delineation of shifting cultivation landscapes and their dynamics:

We calculated landscape metrics using the classified MODIS data. Shifting cultivation can be characterized by a spatio-temporal dynamic of field cultivation (Heinimann 2006; World Bank 2008). Shifting cultivation landscapes show a specific mosaic of the different land cover change trajectories in the classified MODIS data. We used landscape metrics to assess the occurrence and area of land cover change trajectories to delineate shifting cultivation landscapes.

\section{Classification of Landsat Images}

Image Data and Pre-Processing

We used a time series of yearly Landsat images to assess the land cover and its change trajectories. The Landsat path/row
$129 / 46$ proved to be an appropriate image location. It overlaps with those provinces where, based on the available case studies, shifting cultivation is expected to predominate. For each of the years from 2000-2009, a Landsat image was used. Each year's image was taken in the early dry season between October and December, which is the period after harvesting and before clearing new plots for shifting cultivation (Fujisaka 1991; Roder et al. 1997; Yamamoto et al. 2009).

We applied the Tasseled Cap Transformation to the data and calculated the Normalized Difference Vegetation Index (NDVI). Image stacking combined the multispectral image data, the transformed data, and the vegetation index into a single image. Clouds were masked by threshold classification of the Landsat band 1 and the thermal band(s).

Image Classification and Definition of Land Cover Change Trajectories

Several studies have used Landsat images to look at shifting cultivation in northern Laos. Heinimann (2006); Yamamoto et al. (2009), and Inoue et al. (2010) performed postclassification change detection of a binary image classification. Such a classification of each time step into the classes NB and $\mathrm{HB}$ enables the detection of shifting cultivation when using a time series of images (Heinimann 2006; Yamamoto et al. 2009). Post-classification comparison (Fig. 2, section 1 (b)) of the binary image classification provided a complete matrix of the land cover change trajectories occurring, including those representing shifting cultivation and the corresponding crop-fallow rotation cycles (Lu et al. 2004).

As shown in Fig. 2, section 1(a), the Landsat images were basically divided into two classes: NB and HB. In addition, we used the classes "shadow" and "water" to exclude these areas in the analysis of change. This reduced misinterpretations in areas of cloud shadows and edges of water bodies. Following the approach of Robichaud et al. (2009), we selected training sites for the supervised classification on the image using the authors' knowledge of the study area. The images were classified with the support vector machine (SVM) classifier using the tool imageSVM. ImageSVM is an implementation for the classification of remote sensing images with the non-parametric SVM classifier. SVMs constitute machine learning and outperform most other classification approaches (Janz et al. 2007). For each Landsat image the classification accuracy was assessed using a random stratified sample of 50 points per class. The accuracies ranged between $86.5 \%$ and $98.5 \%$.

Subsequently, we removed the classes "shadow" and "water" from the classified images. Post-classification comparison of the 10 images (Fig. 2, section 1(b)) then yielded 1,024 different land cover change trajectories (see Fig. 2, section 1(c)). Each color represents a specific sequence of 
the classes NB and/or HB over the 10 years. The postclassification comparison revealed the spatial distribution of areas with different dates of clearance and/or different crop-fallow rotation cycles, the areas with stable low biomass density, and the areas with stable high biomass density.

\section{Classification of MODIS Data}

\section{Image Data and Pre-Processing}

We analyzed the land cover and land cover changes for northern Laos using the MODIS Enhanced Vegetation Index (EVI) data of the MOD13Q1 product. It provides the EVI as a 16-day composition image, selecting on a pixel basis the best observation of the 16 preceding daily image acquisitions. This provides both a spatial and temporal consistency in vegetation index values (Huete et al. 2002).

Although the data constitutes a 16-day image composition (limiting the problems caused by cloud cover, haze, etc.), the vegetation index values still showed spikes, especially during the months of May to September. Due to the persistent cloud cover in monsoon Asia during the rainy season, certain locations still lacked cloud-free pixels even when multiple images were taken across a period of 16 days. To enhance the data quality by getting rid of these spikes, we processed the images using Timesat (Eklundh and Jönsson 2010; Jönsson and Eklundh 2002, 2004). Timesat fits smooth functions to the data, returning files containing even renditions of the original data, and we used the double logistic function as it showed the best performance. Similar experiences have been reported by other authors dealing with noisy data, e.g. (Beck et al. 2006; Eklundh and Jönsson 2010; Hird and McDermid 2009). We applied the fitting function to data covering the area of northern Laos over the period of 2000-2009.

\section{Image Classification and Definition of Land Cover Change Trajectories}

To classify the MODIS EVI time series, we used the change trajectories derived from the post-classification comparison of the Landsat images. Training areas were thus derived from only one Landsat scene located in the center of northern Laos to classify the MODIS data covering the whole area of northern Laos. See Knorn et al. (2009) for a validation of this approach.

We based the training data selection from the Landsat change trajectories on the approaches of Clark et al. (2010) and DeFries et al. (1999). These authors used a majority cover of a change trajectory within a pixel of the lowresolution data as selection criteria. Considering that the threshold of the majority cover also affects the number of samples that can be derived (the higher the threshold, the fewer samples and vice versa), we found a cover of at least $75 \%$ to be appropriate. We selected a specific change trajectory as a potential training area if it showed at least $75 \%$ cover within a MODIS pixel. This reduced the number of land cover change trajectories considered for the classification of the MODIS EVI time series data from 1,024 to 46. Section 2(a) of Fig. 2 shows an example of the sample selection: the grid represents the size of the MODIS pixels with the points marking the pixels where a land cover change trajectory shows a cover of $75 \%$ or more.

The trajectories of stable HB and stable NB over the tenyear period showed the highest number of training areas for the classification. These two trajectories were followed by the change trajectories showing only one clearance over the decade (each showing nine HB and one NB incidences over the 10 years studied). These ten change trajectories can be related to shifting cultivation land use. Forest (classified as HB) is cleared in one year (resulting in NB), the plot is cultivated and left fallow in the subsequent years (classified as HB) (World Bank 2008). The remaining 34 change trajectories showed different sequences of HB and NB. These may also be related to shifting cultivation (i.e. fallow periods shorter than those mentioned above) or to other land cover dynamics in the region (i.e. the expansion of permanent agriculture). Certain studies on northern Laos report short fallow periods of between 3 and 7 years (de Rouw et al. 2005; Roder et al. 1997; Seidenberg et al. 2003; Sprenger 2006). Most likely these shorter fallow periods are represented by some of the change trajectories with different sequences of HB and NB already described. Most of these change trajectories, however, share the problem that they provide only a very limited number of training areas for classification. In order to assess the importance of the change trajectories within the region we calculated the shares of area they cover within the Landsat training data. Table 1 summarizes this analysis and provides an overview of the included and omitted change trajectories of the classification and their area shares.

The table shows that the change trajectories used as training areas for the classification of the MODIS time series data account for $89 \%$ of the Landsat area. The exclusion of the first group of change trajectories was inevitable as this group included 978 different change trajectories, but covered only $5 \%$ of the Landsat area. None of these change trajectories covered at least $75 \%$ of a MODIS pixel. These dynamics are on a scale that cannot be depicted by the MODIS images and can thus not be included in the classification. The second group of change trajectories excluded consists of 34 different land cover change trajectories and covers only $6 \%$ of the area. While these change trajectories covered more than $75 \%$ of a MODIS pixel, they only provided a limited number of training areas for classification. Using a small number of training areas along with a large number of classes has a negative effect on 
Table 1 Shares of the different change trajectories within the area of the Landsat change trajectories (covering $15,975 \mathrm{~km}^{2}$, change trajectories containing "water" or "shadow" were excluded)

\begin{tabular}{lcr}
\hline Change trajectory groups & $\begin{array}{l}\text { Number of change } \\
\text { trajectories }\end{array}$ & $\begin{array}{c}\text { Percentage } \\
\text { of area }\end{array}$ \\
\hline Stable HB & 1 & 67 \\
Stable NB & 1 & 1 \\
$\begin{array}{l}\text { Included shifting cultivation } \\
\text { change trajectories (once }\end{array}$ & 10 & 21 \\
$\quad$ NB and nine times HB \\
over 10 years)
\end{tabular}

the accuracy of the classification (Pan et al. 2010; Sordo and Zeng 2005; Wästfelt et al. 2012). Including these change trajectories in the classification would thus degrade the accuracy of the whole classification, while excluding them means accepting an inaccuracy that affects $6 \%$ of the study area. We opted for the latter as this would result in a more accurate classification of the change trajectories that represent $89 \%$ of the study area. During the classification process, MODIS pixels showing one of the excluded change trajectories were assigned a class representing one of the change trajectories included in the classification, which was most likely one of the classes representing a change trajectory with only one clearance per year. Such a partial misclassification (as presumably one of the multiple clearances within the 10 years was labeled correctly) was inevitable.

Consequently, stable $\mathrm{HB}$, stable NB, and the ten change trajectories showing only one clearance per year were used as training areas. Figure 3 provides an overview of these change trajectories.
The MODIS EVI time series data was classified with the SVM classifier. In a first run, the classification was performed using imageSVM and the 12 selected classes (Janz et al. 2007). In a second run, a thirteenth class derived from the Landsat images, "stable shadow", was included. This improved the classification output as the terrain shadows in mountainous northern Laos resulted in misclassifications (mainly through terrain shadows being classified as "stable NB"). The class "stable water" was not included, as the water bodies were masked using auxiliary data. Section 2 (b) of Figs. 2 and 4 show the classified MODIS data for selected areas in northern Laos.

Accuracy assessment of the MODIS EVI time series classification was performed using a time series of Landsat images from 2000-2009 in the area of five Landsat scenes $(128 / 46 ; 129 / 45 ; 129 / 46 ; 129 / 47 ; 130 / 46)$ covering most of northern Laos. The image acquisition dates range from October to December. Random stratified sampling of the MODIS classification provided 50 points per class within the Landsat scenes for accuracy assessment and the overall accuracy of the MODIS classification was $81 \%$.

\section{Delineation of Shifting Cultivation Landscapes Using a Landscape Metric Approach}

In order to distinguish those regions under shifting cultivation from those showing other dynamics or processes of change, we considered the characteristics of the different agricultural production systems in northern Laos. Two main systems can be distinguished, namely shifting agriculture, the system of central interest to this study, and different types of permanent agriculture or tree plantations (World Bank 2008). One way to assess whether a landscape is dominated by shifting cultivation is by calculating the $\mathrm{R}$ value (dividing the cultivated area by the area of arable land) (Ruthenberg 1971; van Noordwijk 1999). Unfortunately, the $R$ value could not be calculated in the study at hand as the
Fig. 3 Land cover change trajectories used for the classification of the MODIS EVI time series
2000 - 2001 - 2002 - 2003 - 2004 - 2005 - 2006 - 2007 - 2008 - 2009

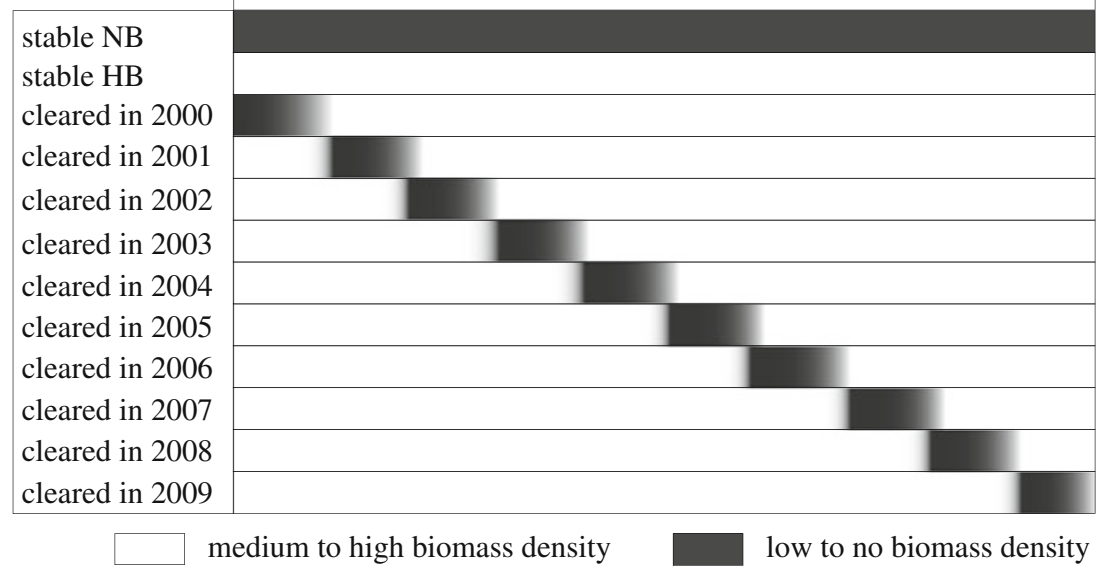


Fig. 4 Major land cover change trajectories, stable $\mathrm{HB}$, and stable NB from 2000 - 2009 classified using time series of MODIS EVI data
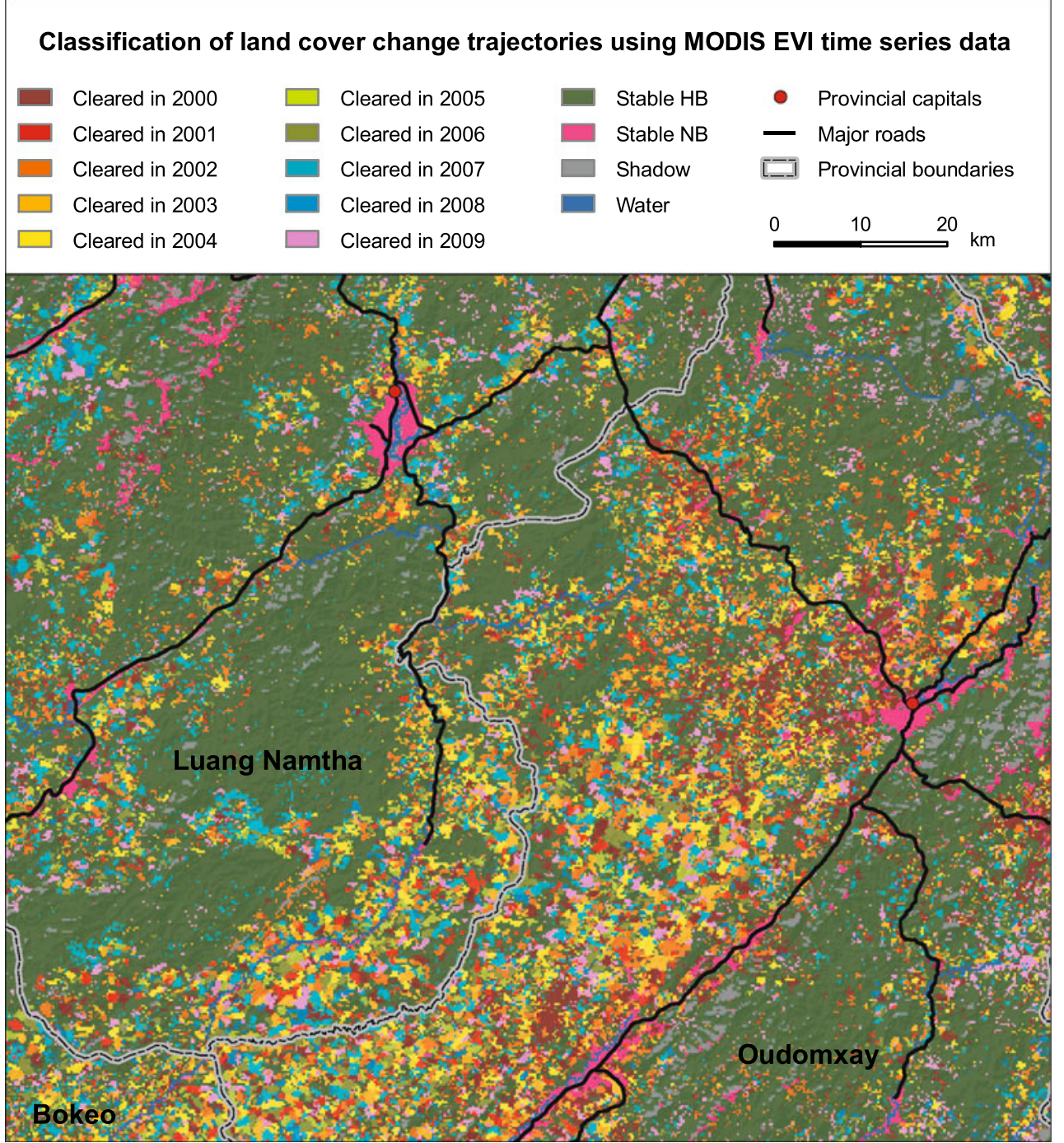

MODIS classification did not show the total area of arable land, but rather the location and time of the prevailing land cover change trajectories. As a result, the spatio-temporal dynamic of plot cultivation could be detected in the MODIS classification and used to distinguish the shifting cultivation system from other systems.

In order to measure the spatio-temporal dynamic, we used landscape metrics, or algorithms that quantify specific spatial characteristics of patches (McGarigal et al. 2002). Within a moving window for each pixel, statistics were calculated based on that pixel's own value and the values of the surrounding pixels. According to Messerli et al. (2009), the window size is a key factor of this analysis, as it should match the average reach of a rural actor. Based on a study showing the impact of accessibility on land cover change, their findings define a window size of $5 \times 5 \mathrm{~km}$ as being meaningful. Within this window size, the regions with shifting cultivation characteristics were assumed to include a low share of the classes "stable HB" and "stable NB", while showing similarly sized shares of each change class. Subsistence production in a shifting cultivation system was presumed to occupy or clear every year similarly sized plots. Other production systems in northern Laos were either already classified as stable NB or, in the case of tree plantations (e.g. teak, rubber), classified as stable HB. Expansion of production systems other than shifting cultivation (e.g. cash cropping and industrial tree plantations) during the 2000-2009 period were likely to be represented as one of the change classes. However, these are one-time changes and do not show the co-occurrence of several change classes in the $5 \times 5 \mathrm{~km}$ window as the production systems with rotational characteristics do (World Bank 2008). In section 3 (a) of Fig. 2, the $5 \times 5 \mathrm{~km}$ grid is displayed along with the classified MODIS data to give an impression of how the change trajectories manifest themselves within the window size used to calculate the landscape metrics.

Prior to the moving window analysis, we removed patches of the change classes covering areas larger than 
650 ha, as they represent dynamics other than those of shifting cultivation (Ducourtieux et al. 2005; Giri et al. 1998; Inoue et al. 2010; Padoch et al. 2007). Using the moving window approach, the following spatial statistics were derived for a $5 \times 5 \mathrm{~km}$ window:

1. Percentage of the area covered by all change classes together

2. Coefficient of variation (CV) of the areas the change classes cover

With these two landscape metrics it was possible to separate the regions where shifting cultivation occurs from areas where no or other production systems mainly prevail. The first landscape metric was used to distinguish areas with land cover changes from the regions where no change occurred. The second metric provided information on how the change classes were represented in the area the moving window covered. A low CV indicated that the change classes covered more or less equal area shares within the moving window while a high $\mathrm{CV}$ indicated the opposite. The regions where shifting cultivation prevailed as the predominant land use practice were characterized by a high area share of change classes, as well as a low $\mathrm{CV}$ of the areas of the change classes within the moving window.

As stressed by Mertz et al. (2009), it is also important to map the dynamics of the landscapes dominated by shifting cultivation. The MODIS classification, showing the predominant land cover change trajectories over 10 years, allowed for such an analysis. We calculated the shifting cultivation areas for the periods of 2000-2006 and 20032009. Change classes not used for the calculation of the shifting cultivation area (i.e. for 2000-2006, those classes showing change in 2007, 2008, and 2009) were considered as belonging to the class of "stable HB". Figure 5 shows the shifting cultivation landscapes from 2000-2006 together with the classified land cover change trajectories used for
Fig. 5 Landscapes where shifting cultivation prevails from 2000 - 2006. In the background is the MODIS classification of land cover change trajectories, stable $\mathrm{HB}$, and stable NB usedto calculate the landscape metrics

\section{Landscape dominated by shifting cultivation between 2000 and 2006}

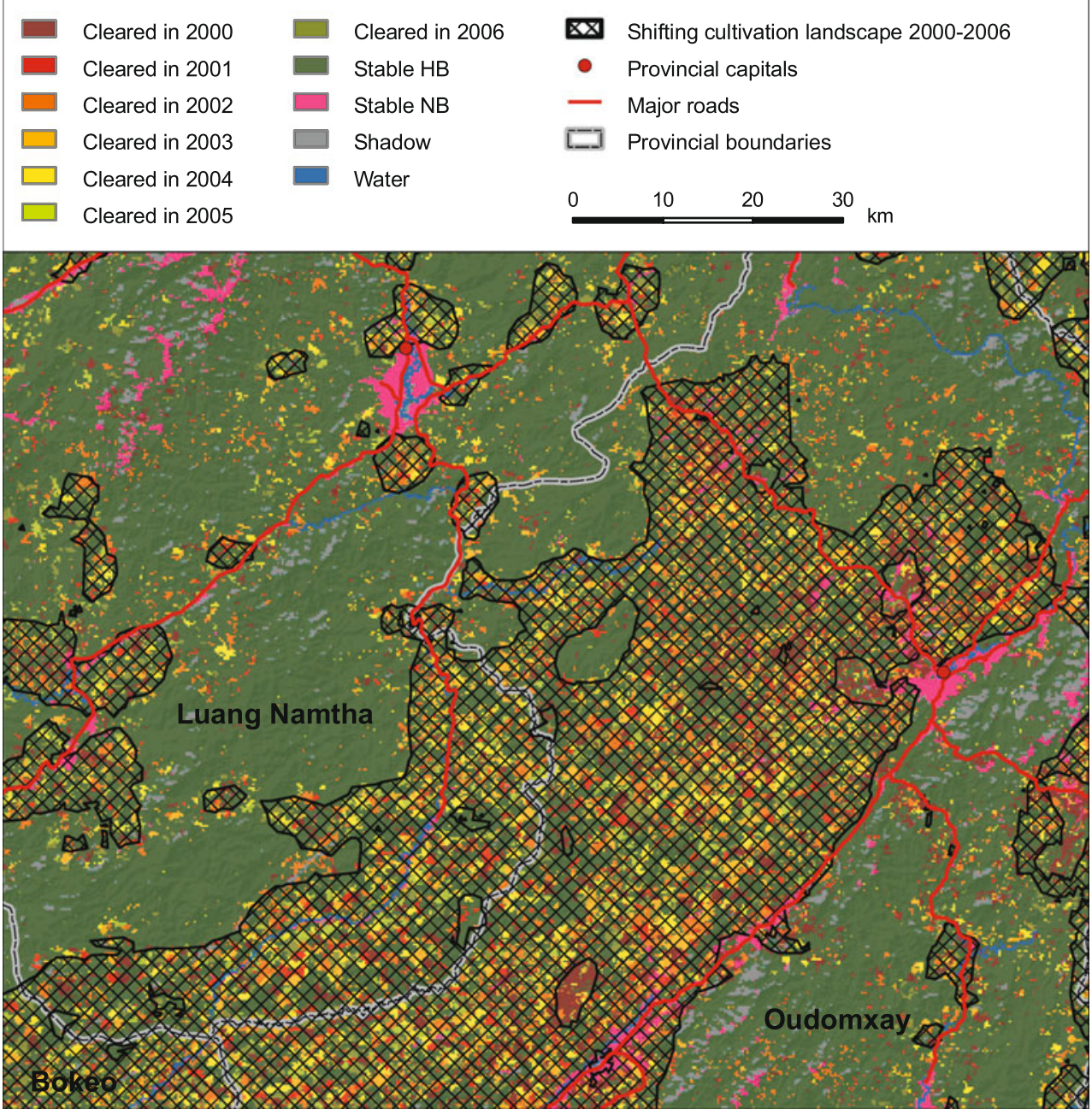


delineation (change trajectories "cleared in 2007", "cleared in 2008" and "cleared in 2009" are included in the class "stable HB").

Combining the two time steps revealed the areas where shifting cultivation had disappeared as the dominant land use from 2000-2003, where it had remained predominant from 2000-2009, and where it had emerged as the predominant land use from 2006-2009. In Fig. 6, the dynamics of shifting cultivation landscapes in northern Laos are presented.

It would have been ideal to assess the dynamics using two time periods from 2000-2004 and 2005-2009. However, as the landscape metrics are based on the change classes, a better estimate of the area where shifting cultivation prevailed can be provided when a longer period is considered. We found the calculation of the landscape metrics for a period of 7 years (2000-2006 and 2003-2009) to be appropriate.
Validation of the Delineated Shifting Cultivation Landscapes

Field verification of the delineated shifting cultivation landscapes over space and time was beyond the capacity of this study and a verification using time series of medium to high resolution satellite images was limited by data availability and the subjective spatial interpretation of the dynamics by the researcher. Therefore, we chose a cost-effective approach that still allowed a certain accuracy statement: 13 publications on shifting cultivation in northern Laos (looking at 39 villages) from 2000-2006 were used to assess the shifting cultivation landscape delineated by our analysis. Only one article with a study period later than 2006 was available; therefore, this assessment was only performed for the period from 2000-2006. Still, for both of the periods, the delineation of the area where shifting cultivation prevailed
Fig. 6 Shifting cultivation dominated landscapes and their dynamics from $2000-2009$ in northern Laos

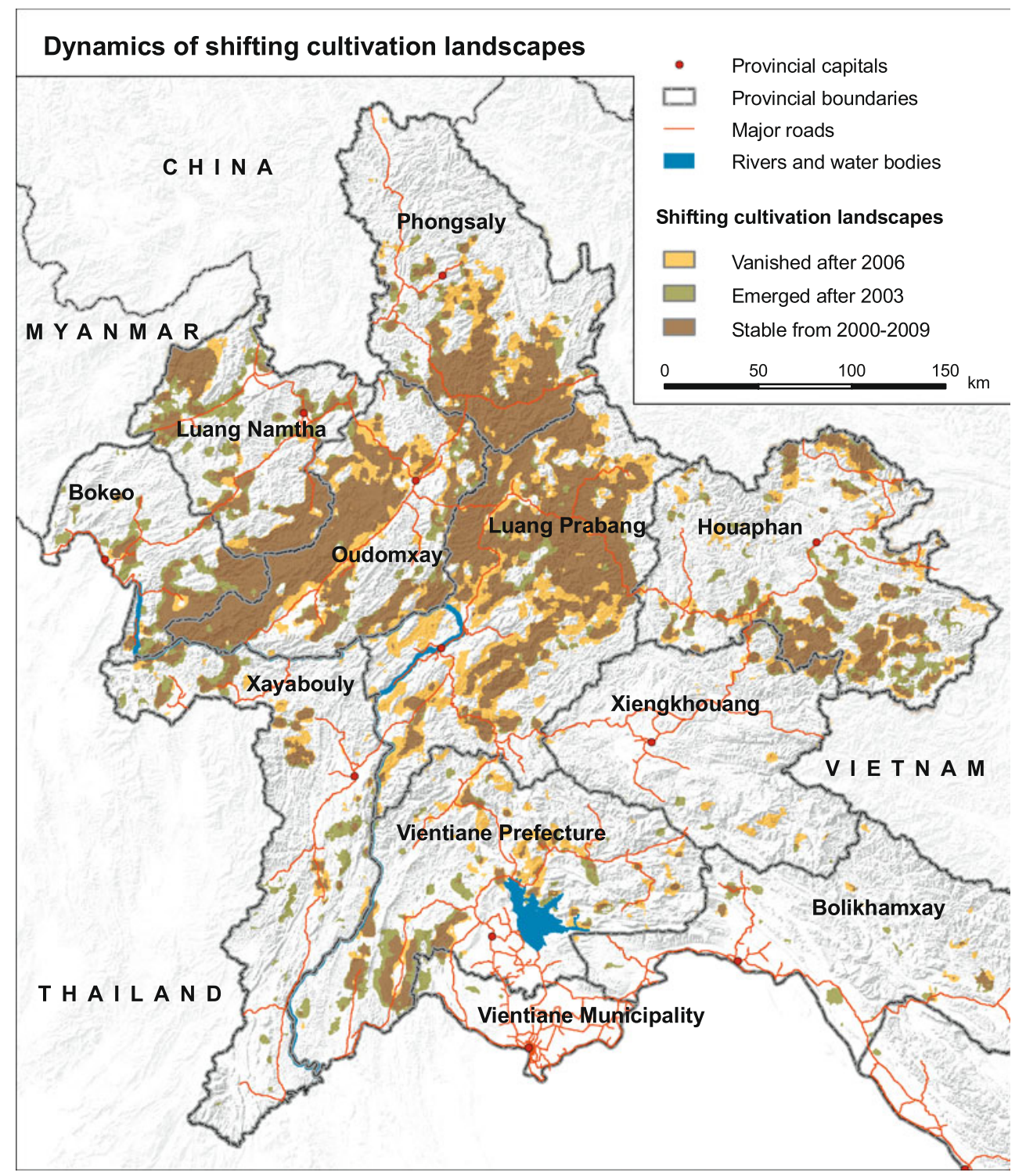


was derived from the same MODIS EVI classification by using the same methodology; thus levels of accuracy can be assumed to be similar.

The validation was one-sided; we could only test whether the villages reported to have shifting cultivation also contained shifting cultivation areas mapped from the MODIS data. Unfortunately we could not check the reverse, as studies looking at other land use practices or land cover types within a certain area do not necessarily exclude the possibility of the co-occurrence of a shifting cultivation practice (Schmidt-Vogt et al. 2009). Consequently, the validation provided an error of exclusion (or omission error excluding an area from a category to which it belongs), but not an error of inclusion (or commission error - including an area in a category it does not belong) (Congalton et al. 1998; Delang 2007).

A list of case study villages of publications used and their share of land mapped as shifting cultivation for the period 2000-2006 is given in Table 2.

Five villages reported to be practicing shifting cultivation did not overlap with the mapped shifting cultivation area, while 17 villages revealed a $100 \%$ overlap. We considered calculating the error of exclusion using the shares of overlap as inappropriate. On the one hand, we do not know what other types of land use or land cover occurred in the villages (e.g. paddy fields, grasslands, unused forest areas). On the other hand, the map is suitable for the provincial level, taking into consideration the resolution of the MODIS data and the additional moving window analysis (Bagan et al. 2005; Foody 2002; Hansen et al. 2005). In order to check whether the distribution of the mapped shifting cultivation area was accurate, we performed a binary assessment by dividing the villages into "shifting cultivation villages" and "not shifting cultivation villages". Villages showing a shifting cultivation share of $30 \%$ or more were assumed to be "shifting cultivation villages", the others not. This resulted in an error of exclusion of $77 \%$, or in other words, $77 \%$ of the shifting cultivation villages are labeled as such on the map.

\section{Results and Discussion}

\section{Approach}

We found the three-step approach appropriate for mapping landscapes dominated by shifting cultivation on a regional or national level. First, through a post-classification comparison of yearly Landsat images, we gained information on the land cover change trajectories occurring. In the second step, we mapped the prevailing land cover change trajectories for the whole region using MODIS time series data. Third, we used landscape metrics to take into account the spatio-temporal dynamics of land cover change trajectories related to shifting cultivation. This allowed us to map landscapes dominated by shifting cultivation and their dynamics and, based on the accuracy assessments, the three-step approach developed worked well. Performing an accuracy assessment of the output of each step of the approach independently ensured that no classification errors accumulated without being quantified.

\section{Classification of Landsat Images}

The Landsat analysis in the first step provided information on the incidence and spatial distribution of the different processes occurring in northern Laos. The accuracy of the classified Landsat images ranged from $86.5-98.5 \%$. This confirmed the findings of the study of Heinimann (2006), who demonstrated that a binary classification into high and low biomass classes of Landsat images is very robust.

The post-classification comparison of the Landsat classification provided a complete matrix of the land cover change trajectories and their frequency. This allowed a quantification of the dynamics occurring in the area of the Landsat scene. In Table 1, we showed that out of the 1024 land cover change trajectories mapped (not including the classes "water" and "shadow"), it is possible to explain $89 \%$ of the dynamics in the area with only 12 change trajectories. Over the 10 years analyzed, $68 \%$ of the area showed a stable land cover $(67 \%$ stable $\mathrm{HB}$, and $1 \%$ stable $\mathrm{NB})$. At least $21 \%$ of the area displayed change trajectories that could clearly be related to shifting cultivation (showing nine incidences of $\mathrm{HB}$ and one of NB over the decade analyzed). The remaining $11 \%$ of the area showed a great variety of dynamics, as it is represented by 978 different change trajectories. Considering the high number of change trajectories within this small area, it can be assumed that each change trajectory covers only a small area and/or is relevant for a specific location rather than for the whole study region. These change trajectories may also be related to shifting cultivation (with different sequences of $\mathrm{HB}$ and NB over the decade) and to other land cover dynamics, for example the expansion of permanent agriculture.

\section{Classification of MODIS Data}

Classification of the prevailing land cover change trajectories for northern Laos was performed using MODIS time series data as a consistent time series of Landsat images was not available for this area. Therefore, the medium spatial resolution of the Landsat data had to be sacrificed for a lower spatial resolution, but a high temporal resolution of the MODIS data. As the different land cover change trajectories represent specific temporal patterns of vegetation dynamics, the high temporal resolution was a benefit. 
Table 2 Share of the village area being mapped as "predominated by shifting cultivation"

\begin{tabular}{|c|c|c|c|}
\hline Publication & Village Name & Study Period & Shifting Cultivation Area Share (\%) \\
\hline Linquist et al. (2007) & B. Namo-Nua & $1962-2002$ & 68 \\
\hline Linquist et al. (2007) & B. Pangdou & $1962-2002$ & 97 \\
\hline Linquist et al. (2007) & B. Houayluang & $1962-2002$ & 95 \\
\hline Linquist et al. (2007) & B. Houaythoum & $1962-2002$ & 99 \\
\hline Linquist et al. (2007) & B. Pakchek & 1962-2002 & 100 \\
\hline Linquist et al. (2007) & B. Khonkham & $1962-2002$ & 100 \\
\hline Linquist et al. (2007) & B. Houayman & $1962-2002$ & 0 \\
\hline Linquist et al. (2007) & B. Thapho & $1962-2002$ & 41 \\
\hline Watanabe et al. (2004) & B. Phonxai & 2000 & 97 \\
\hline Watanabe et al. (2004) & B. Thinkeo & 2000 & 88 \\
\hline Watanabe et al. (2004) & B. Longluat & 2000 & 100 \\
\hline Seidenberg et al. (2003) & B. Phiangxai & 2000 & 26 \\
\hline Seidenberg et al. (2003) & B. Khangkhao & 2000 & 30 \\
\hline Seidenberg et al. (2003) & B. Keoxik & 2000 & 54 \\
\hline Sprenger (2006) & B. Takheung & $2000-2005$ & 100 \\
\hline Yokoyama (2004) & B. Hommok & 2001 & 71 \\
\hline Yokoyama (2004) & B. Cheng-Kang & 2001 & 100 \\
\hline Yokoyama (2004) & B. Pakbout & 2001 & 100 \\
\hline Yokoyama (2004) & B. Houaylo-Theung & 2001 & 100 \\
\hline Yokoyama (2004) & B. Kongmouang & 2001 & 100 \\
\hline Yokoyama (2004) & B. Paklong & 2001 & 100 \\
\hline Yokoyama (2004) & B. Houaylo-Soung & 2001 & 96 \\
\hline Yokoyama (2004) & B. Houaysi & 2001 & 100 \\
\hline Yokoyama (2004) & B. Hatsa & 2001 & 100 \\
\hline Yokoyama (2004) & B. Phonxana & 2001 & 100 \\
\hline Yokoyama (2004) & B. Gnotsi & 2001 & 100 \\
\hline Saito et al. (2006) & B. Hatmat & $2001-2002$ & 0 \\
\hline Saito et al. (2006) & B. Houaykha & $2001-2002$ & 99 \\
\hline Saito et al. (2006) & B. Phathung & $2001-2002$ & 100 \\
\hline Saito et al. (2006) & B. Somsanouk & $2001-2002$ & 10 \\
\hline de Rouw et al. (2005) & B. Lak10 & $2001-2003$ & 0 \\
\hline LSUAFRP (2003) & B. Kioulan & 2002 & 21 \\
\hline LSUAFRP (2003) & B. Pangthong & 2002 & 100 \\
\hline Ducourtieux (2005) & B. Yapoung & $2002-2003$ & 7 \\
\hline Ducourtieux (2005) & B. Tete & $2002-2003$ & 1 \\
\hline Darr (2003) & B. Napo & $2002-2003$ & 0 \\
\hline Yokoyama et al. (2006) & B. Naxao & 2003 & 0 \\
\hline Alton et al. (2005) & B. Hatgnao & 2004 & 86 \\
\hline Leek (2007) & B. Mang & 2006 & 100 \\
\hline
\end{tabular}

The assessment of the $75 \%$ majority cover of the Landsat change trajectories within a MODIS pixel for the sample selection had an additional benefit. It allowed us to assess the potential of the scale of the MODIS data to map land cover change trajectories in northern Laos. This analysis showed that the MODIS data is able to detect land cover change trajectories that represent $94.5 \%$ of the area. Using MODIS, it is thus possible to map most of the land cover changes in northern Laos. In our analysis, however, we used only the 12 most frequently occurring land cover change trajectories, thus covering $89 \%$ of the study area. The reason for doing so was the very limited amount of training data that could be retrieved from the other land cover change trajectories (a small number of training areas reduces the classification accuracy). A higher number of classes also results in a less accurate classification (Pan et al. 2010; Sordo and Zeng 2005; Wästfelt et al. 2012). This approach thus increased the accuracy of the classes representing $89 \%$ 
of the change trajectories, while we accepted a misclassification of $11 \%$ of the occurring land cover change trajectories. The classification of the MODIS data resulted in an overall accuracy of $81 \%$.

Although most of the changes occurring in northern Laos can be depicted using MODIS data, the low spatial resolution compromised the problem of mixed pixels. During the classification, these pixels were assigned only one of the multiple classes they represent. As a result, the classification of these pixels can be considered neither completely wrong nor completely right (Congalton et al. 1998; Foody 2002). Comparing the change in areas of the different classes was therefore inappropriate. However, we were able to overcome this limitation of the MODIS classification by looking at the spatiotemporal dynamics using landscape metrics (Heinimann 2006; Schmidt-Vogt et al. 2009; Yamamoto et al. 2009).

\section{Landscape Metrics}

The output of the landscape metrics showed the extent of shifting cultivation landscapes for the years 2000-2006 and 2003-2009. Verification of the delineated shifting cultivation landscapes resulted in an error of exclusion of $77 \%$ ( $77 \%$ of the shifting cultivation villages are labeled as such on the map). As discussed, the verification of this step is limited, thus no error of inclusion or overall accuracy could be provided. Additionally, the assessment could only be performed for the first period of the delineated shifting cultivation landscapes (2000-2006) as the second period (2003-2009) lacked relevant literature. This is not considered a critical shortcoming as the accuracy can be expected to be similar, especially as the contextual interpretation of the results below shows that the mapped dynamics are in line with respective known processes.

\section{Interpretation of Results}

Our data shows that shifting cultivation landscapes are still widespread throughout northern Laos. The provinces of Luang Prabang, Phonsaly, Oudomxay, Bokeo, and Luang Namtha can be considered to host the core area under shifting cultivation in northern Laos (see Fig. 6). In these provinces, shifting cultivation landscapes are vast and spatially continuous. Two major patches can be identified, one across much of Luang Prabang and southern Phongsaly provinces and the other around the borders of Oudomxay, Luang Namtha and Bokeo provinces.

In the other provinces of northern Laos, shifting cultivation landscapes are also found, but they cover smaller, patchy areas.

The analysis of our data from the two time periods showed that the area of shifting cultivation dominated landscapes in northern Laos decreased by almost $10 \%$ (from $35,140 \mathrm{~km}^{2}$ in $2000-2006$ to $31,640 \mathrm{~km}^{2}$ in $2003-2009$ ). An overview of these dynamics is given in Table 3 .

The net change in landscapes dominated by shifting cultivation constitutes only $2.2 \%$ of the study area. However, an examination of emerging and disappearing shifting cultivation landscapes reveals that both are very dynamic. On the one hand, the landscapes dominated by shifting cultivation from 2000-2006 were reduced by $30 \%$, with almost one third of the area under shifting cultivation in this period changing to another land use after 2006. On the other hand, some shifting cultivation areas emerged in landscapes that were not used for shifting cultivation from 2000-2002. Within the area of landscapes dominated by shifting cultivation from 2003-2009, $23 \%$ had not been used for shifting cultivation from 2000-2002. With the MODIS EVI time series data and analysis only dating back to the year 2000, there is no direct evidence that there was no shifting cultivation in these areas before 2000 (i.e. areas may have been under a long fallow period, thus no activity was observed from 2000-2002). However, the size of the moving window used to calculate the landscape metrics as well as the spatial distribution of the emerging shifting cultivation landscapes suggest that this dynamic represents an expansion and is not just a result of a long fallow that was not covered by the analysis period.

Given the highly dynamic nature of shifting cultivation landscapes, not only their net change but also the spatial distribution of their changes as depicted in Fig. 6 should be considered. As already described, the core regions of shifting cultivation were those most affected by the decrease, with the biggest decreases being observed around the provincial capitals of Luang Prabang and Oudomxay, and around Phongsaly. Those areas where shifting cultivation has emerged as the dominant land use seem to be more

Table 3 Area and dynamics of landscapes dominated by shifting cultivation in northern Laos

\begin{tabular}{lllll}
\hline & $\begin{array}{l}\text { Shifting cultivation } \\
\text { dominated landscapes } \\
2000-2006\end{array}$ & $\begin{array}{l}\text { Shifting cultivation } \\
\text { dominated landscapes } \\
2003-2009\end{array}$ & $\begin{array}{l}\text { Emerging shifting } \\
\text { cultivation landscapes } \\
\text { after 2003 }\end{array}$ & $\begin{array}{l}\text { Disappearing shifting } \\
\text { cultivation landscapes } \\
\text { after 2006 }\end{array}$ \\
\hline Area in $\mathrm{km}^{2}$ & 35,140 & 31,640 & 7,300 & 10,800 \\
Share of total study area & $22 \%$ & $19.8 \%$ & $4.6 \%$ & $6.8 \%$ \\
\hline
\end{tabular}


widely dispersed throughout northern Laos. Regions which are easily accessible, as well as the rather peripheral ones both show patches of new shifting cultivation landscapes. While the demise of shifting cultivation in most provinces outweighs its rise, Luang Namtha and Bokeo show an increase. An overview of the dynamics of the area under shifting cultivation in the northern provinces of Laos is given in Table 4.

As can be seen in Table 4, the dynamics of landscapes dominated by shifting cultivation vary greatly between the provinces of northern Laos. Though it is beyond the scope of this study to analyze the drivers that could have led to these different dynamics, we reviewed relevant reports and journal articles in order to shed some light on the land cover changes. While such an analysis does not constitute evidence on the drivers of change, it does highlight the spatial variability of factors affecting shifting cultivation landscapes in northern Laos and the importance of further research in this field.

Given the very swift market integration of more accessible areas of northern Laos in the last decade, the decrease observed in shifting cultivation landscapes, especially in Luang Prabang and Oudomxay, is not surprising (Fox et al. 2009). Around provincial capitals and along roads, the accessibility of domestic and international markets (especially those of the neighboring countries of China, Thailand, and Vietnam) has led to an increase in the permanent cultivation of not only rice, maize, and sesame but also of tree crops, and a consequent decrease in the practice of shifting cultivation (Alexander et al. 2010; Leek 2007). Meanwhile,

Table 4 Changes in the shifting cultivation landscapes in the northern provinces of Laos between the periods 2000-2006 and 2003-2009. The two time steps overlap as the methodology used to identify shifting cultivation landscapes required a time span of 7 years for a reliable delineation

\begin{tabular}{lcc}
\hline Province & $\begin{array}{l}\text { Area covered by } \\
\text { shifting cultivation } \\
\text { landscapes 2000-2006 } \\
\text { in \% of total area }\end{array}$ & $\begin{array}{l}\text { Area covered by } \\
\text { shifting cultivation } \\
\text { landscapes 2003-2009 } \\
\text { in \% of total area }\end{array}$ \\
\hline Luang Prabang & 56.3 & 39.8 \\
Oudomxay & 55.7 & 47.1 \\
Phongsaly & 28.9 & 25.6 \\
Luang Namtha & 27.1 & 36.5 \\
Houaphan & 23.7 & 22.1 \\
Bokeo & 21.6 & 30.3 \\
Vientiane & 13.0 & 11.7 \\
$\quad$ Prefecture & 7.8 & 9.8 \\
Xayabouly & 4.8 & 3.2 \\
Xiengkhouang & 1.7 & 2.2 \\
Bolikhamxay & 1.1 & 4.6 \\
Vientiane & & \\
Municipality & & \\
\hline
\end{tabular}

in the east of Laos, in Houaphanh Province, the reduction in the area where shifting cultivation prevails may very well be related to increased market integration. Infrastructure investments and reduced taxes for exports to Vietnam have encouraged farmers in Houaphan Province to switch to the production of cash crops like maize, vegetables, and even cotton (Viau et al. 2009). The land use planning and land allocation program, one of the government tools to stabilize and eradicate shifting cultivation, may also have affected the reduction of shifting cultivation. Still, the (unregulated) increase of market based economies has clearly been the dominant force behind changes in shifting cultivation in the majority of provinces in northern Laos (Ducourtieux et al. 2006; Lestrelin 2010; Nowak et al. 2008).

The provinces of Bokeo and Luang Namtha have been exposed to increasing market forces in a similar manner. Nevertheless, a net increase in shifting cultivation landscapes was detected between the two periods considered in this paper (cf. Table 4). This relates to the large expansion of smallholder rubber plantations since 2003 as a response to the Chinese demand for rubber (Shi 2008). According to Alton et al. (2005) rubber is being planted on land previously under short-term fallow. During the first 2 years, rubber is intercropped with upland rice, but in the third year, rice yields decline. As income from rubber can only be generated after 7 years (when the trees are big enough for the latex to be tapped), farmers encroach on forest areas and previously unused land for food security reasons. This (temporary) expansion of the shifting cultivation areas from 2006-2009 related to the establishment of many young rubber plantations can be confirmed by our results. Aside from the expansion of rubber plantations, growing population pressure on allocated land is also a factor in the expansion of the shifting cultivation area mapped. Thongphanh et al. (2011) found that in Bokeo Province, people returned to shifting cultivation after the land allocation process due to the shortage of the allocated agricultural land. While no causality can be concluded from the data itself, the findings reviewed contribute great insight into the rise in the total area under shifting cultivation in Bokeo and Luang Namtha provinces.

It is interesting to note that Xayabouly Province in western Laos, which has seen an extraordinary expansion of maize grown for export to the neighboring Thai market since early 2000, now shows a counter intuitive slight increase in shifting cultivation landscapes. Ducourtieux et al. (2005) indeed reveal a connection between the expansion of the shifting cultivation area, the expansion of maize production and the land allocation policy. Poorer families are forced to continue with shifting cultivation for food security reasons, to invest in allocated land (e.g. in chemical fertilizers), or to pay taxes for allocated land. Additionally, after land allocation, the wealthier families tend to hold more 
land than the poor. When this land is not being used for cash crops, poorer families borrow it for upland rice cultivation. However, the mediocre quality and the insecure tenure of the borrowed plots force the families to clear protected forest hilltop areas as well. Even though there are fines for doing so, these are perceived more as the price of access to the land than penalties. Last but not least clandestine slashing is also performed by wealthier families in order to expand their agricultural land.

A similar pattern to that found in Xayabouly Province is expected to surface in Vientiane Province. In recent years, commercial agriculture has expanded rapidly along roads, replacing shifting cultivation with more permanent systems (largely maize based). Nevertheless, rice based shifting cultivation, which is still necessary for certain population segments (see above), increased partly through encroachment into older bush fallows and occasionally into forest areas distant from roads.

\section{Conclusion and Recommendations}

Our presented approach is based on data that for the most part is available free of charge. As MODIS makes it possible to cover large areas, this approach has the potential to detect and monitor shifting cultivation dominated landscapes beyond northern Laos at regular intervals. The main shortcoming is related to the limited time span covered by our study rather than to the methodology itself. Using the MODIS data in combination with landscape metrics makes it difficult to separate the recent smallholder conversion of forest or fallow land to permanent agricultural land from the rotational characteristics of shifting cultivation. An analysis of a longer time series could resolve this problem by showing whether the changes are of a permanent or a temporary nature. This could reveal whether shifting cultivation will disappear in Luang Namtha Province as soon as more rubber plantations mature to tapping age. Similarly, in Xayabouly Province, a longer time series could more accurately distinguish between those regions under shifting cultivation and those that are undergoing smallholder expansion of permanent agriculture.

The results of this study represent an innovation in generating spatially coherent data on the extent and the dynamics of shifting cultivation landscapes. This allowed for the interpretation of the observed dynamics using information from reports and studies on land use and land cover transformations in northern Laos. The review of reports and journal articles indicates that in the center of northern Laos, policies and economic forces have led to the expected reduction in shifting cultivation landscapes, while in Luang Namtha Province, Chinese demand for rubber has led to a boom in rubber plantations and to a presumably temporary expansion of shifting cultivation into formerly unused areas (Alexander et al. 2010; Alton et al. 2005; Fox et al. 2009; Leek 2007). Xayabouly Province showed similar dynamics, but the underlying causes seem to be related to land allocation policy and to the Thai demand for maize there (Ducourtieux et al. 2005).

Our findings underline the importance of further research related to the delineation of the extent and dynamics of shifting cultivation landscapes as well as the analysis of the underlying drivers of change. Using a longer time series of remote sensing data could improve the assessment of the dynamics of shifting cultivation landscapes. However, a longer time series also means more change trajectories and thus the inclusion of more classes in the analysis. Further research is required to assess how to best deal with the interlinked problems of overall classification accuracy, the greater number of classes, and the highly varying number of training areas within these classes available for classification. With regards to the drivers of change, the review of reports and articles did not allow a spatially consistent interpretation of the dynamics. Regardless, it indicated how different configurations of market forces and policies effect changes in the areas dominated by shifting cultivation. On the basis of the existing spatially coherent data of the area dominated by shifting cultivation and its dynamics, further research should focus on spatially explicit analyses of the interactions between policies, socio-economic characteristics, and influences of the (international) markets in these areas. This would give insight into the trade-offs between the different factors that lead to transformation processes in the areas dominated by shifting cultivation.

Acknowledgments This work was supported by the Swiss National Centre of Competence in Research (NCCR) North-South and cofunded by the Swiss National Science Foundation (SNF) and the Swiss Agency for Development and Cooperation (SDC). Furthermore, this research has benefited from collaborations of the I-REDD+ project of the European Commission Framework Project (FP7-ENV-2010), The Agrobiodiversity Initiative in Lao PDR (TABI) project funded by SDC as well as a grant from the Danish Social Science Research Council, and the exchange within the Global Land Project (GLP)

\section{References}

Alexander, K. S., Millar, J., and Lipscombe, N. (2010). Sustainable development in the uplands of Lao PDR. Sustainable Development 18(1): 62-70.

Alton, C., Blum, D., and Sananikone, S. (2005). Para Rubber Study: Hevea Brasiliensis Lao PDR. GTZ, Lao German Program Rural Development in Mountainous Areas of Northern Lao PDR. Vientiane, Lao PDR

Bagan, H., Wang, Q., Watanabe, M., Yang, Y., and Ma, J. (2005). Land cover classification from MODIS EVI times-series data using SOM neural network. International Journal of Remote Sensing 26(22): 4999-5012. 
Beck, P. S. A., Atzberger, C., Høgda, K. A., Johansen, B., and Skidmore, A. K. (2006). Improved monitoring of vegetation dynamics at very high latitudes: A new method using MODIS NDVI. Remote Sensing of Environment 100(3): 321-334.

Clark, M. L., Aide, T. M., Grau, H. R., and Riner, G. (2010). A scalable approach to mapping annual land cover at $250 \mathrm{~m}$ using MODIS time series data: A case study in the Dry Chaco ecoregion of South America. Remote Sensing of Environment 114(11): 28162832.

Congalton, G. R., Balogh, M., Bell, C. A., Green, K., Milliken, J. A., and Ottman, R. (1998). Mapping and Monitoring Agricultural Crops and Other Land Cover in the Lower Colorado River Basin. Photogrammetric Engineering and Remote Sensing 64(11): 7.

Cramb, R., Colfer, C., Dressler, W., Laungaramsri, P., Le, Q., Mulyoutami, E., Peluso, N., and Wadley, R. (2009). Swidden Transformations and Rural Livelihoods in Southeast Asia. Human Ecology 37(3): 323-346.

Darr, D. (2003). Farm forestry in semi-subsistence and monetary economies and its interdependency with the land tenure system Case studies from central Laos [MSc Thesis]. Dresden University of Technology, Faculty of Forest, Geo and Hydro Sciences, Dresden, Germany

de Rouw, A., Soulilad, B., Phanthavong, K., and Dupin, B. (2005). In Bouahom, B., Glendinning, A., Nilsson, S., and Victor, M. (eds.), The adaptation of upland rice cropping to ever-shorter fallow periods and its limit. Poverty reduction and shifting cultivation stabilisation in the uplands of Lao PDR. NAFRI, Vientiane, pp. 139-148.

DeFries, R. S., Townshend, J. R. G., and Hansen, M. C. (1999). Continuous fields of vegetation characteristics at the global scale at 1-km resolution. Journal of Geophysical Research 104(D14): $16,911-16,923$.

Delang, C. O. (2007). Ecological Succession of Usable Plants in an Eleven-Year Fallow Cycle in Northern Lao P.D.R. Ethnobotany Research and Applications 5: 331-350.

Dorren, L. K. A., Maier, B., and Seijmonsbergen, A. C. (2003). Improved Landsat-based forest mapping in steep mountainous terrain using object-based classification. Forest Ecology and Management 183(1-3): 31-46.

Ducourtieux, O. (2005). In Bouahom, B., Glendinning, A., Nilsson, S., and Victor, M. (eds.), Shifting cultivation and poverty eradication: A complex issue. Poverty reduction and shifting cultivation stabilisation in the uplands of Lao PDR. NAFRI, Vientiane, pp. 71-94.

Ducourtieux, O., Laffort, J. R., and Sacklokham, S. (2005). Land Policy and Farming Practices in Laos. Development and Change 36(3): 499-526.

Ducourtieux, O., Visonnavong, P., and Rossard, J. (2006). Introducing Cash Crops in Shifting Cultivation Regions - The Experience with Cardamom in Laos. Agroforestry Systems 66(1): 65-76.

Eklundh, L., and Jönsson, P. (2010). TIMESAT 3.0 - Software Manual. Lund University, Lund.

Foody, G. M. (2002). Status of land cover classification accuracy assessment. Remote Sensing of Environment 80(1): 185-201.

Fox, J., Fujita, Y., Ngidang, D., Peluso, N., Potter, L., Sakuntaladewi, N., Sturgeon, J., and Thomas, D. (2009). Policies, PoliticalEconomy, and Swidden in Southeast Asia. Human Ecology 37 (3): 305-322.

Fujisaka, S. (1991). A diagnostic survey of shifting cultivation in northern Laos: targeting research to improve sustainability and productivity. Agroforestry Systems 13(2): 95-109.

Giri, C. P., Pradhan, D., Ofren, R. S., and Kratzschmar, E. (1998). Land use/land cover change in South-East Asia. Environment Assessment Technical Reports. UNEP Environment Assessment Programme for Asia and the Pacific, Bangkok.

Hansen, M. C., Townshend, J. R. G., DeFries, R. S., and Carroll, M. (2005). Estimation of tree cover using MODIS data at global, continental and regional/local scales. International Journal of Remote Sensing 26(19): 4359-4380.

Heinimann, A. (2006). Patterns of Land Cover Change in the Lower Mekong Basin: The relevance of mesoscale approaches $[\mathrm{PhD}$ Thesis]. University of Berne, Philosophisch-naturwissenschaftlichen Fakultät, Berne

Hett, C., Heinimann, A., and Messerli, P. (2011). Spatial assessment of carbon stocks of living vegetation at the national level in Lao PDR. Geografisk Tidsskrift-Danish Journal of Geography 111(1): $11-26$.

Hird, J. N., and McDermid, G. J. (2009). Noise reduction of NDVI time series: An empirical comparison of selected techniques. Remote Sensing of Environment 113(1): 248-258.

Huete, A., Didan, K., Miura, T., Rodriguez, E. P., Gao, X., and Ferreira, L. G. (2002). Overview of the radiometric and biophysical performance of the MODIS vegetation indices. Remote Sensing of Environment 83(1-2): 195-213.

Inoue, Y., Qi, J., Olioso, A., Kiyono, Y., Horie, T., Asai, H., Saito, K., Ochiai, Y., Shiraiwa, T., and Douangsavanh, L. (2007). Traceability of slash-and-burn land-use history using optical satellite sensor imagery: a basis for chronosequential assessment of ecosystem carbon stock in Laos. International Journal of Remote Sensing 28(24): 5641-5647.

Inoue, Y., Kiyono, Y., Asai, H., Ochiai, Y., Qi, J., Olioso, A., Shiraiwa, T., Horie, T., Saito, K., and Dounagsavanh, L. (2010). Assessing land-use and carbon stock in slash-and-burn ecosystems in tropical mountain of Laos based on time-series satellite images. International Journal of Applied Earth Observation and Geoinformation 12(4): 287-297.

Janz, A., van der Linden, S., Waske, B., and Hostert, P. (2007). imageSVM - A user-oriented tool for advanced classification of hyperspectral data using support vector machines. 5th EARSeL Workshop on Imaging Spectroscopy. Bruges, Belgium.

Jönsson, P., and Eklundh, L. (2002). Seasonality Extraction by Function Fitting to Time-Series of Satellite Sensor Data. IEEE Transactions on Geoscience and Remote Sensing 40(8): 1824 1832.

Jönsson, P., and Eklundh, L. (2004). TIMESAT-a program for analyzing time-series of satellite sensor data. Computers \& Geosciences 30(8): 833-845.

Knorn, J., Rabe, A., Radeloff, V. C., Kuemmerle, T., Kozak, J., and Hostert, P. (2009). Land cover mapping of large areas using chain classification of neighboring Landsat satellite images. Remote Sensing of Environment 113(5): 957-964.

Leek, K. E. (2007). Rural Livelihood Strategies and Natural Resources in Oudomxay, Lao PDR [MSc Thesis]. University of Natural Resources and Applied Life Sciences, Vienna; Lincoln University, Christchurch, NZ, Natural Resources Management and Ecological Engineering.

Lestrelin, G. (2010). Land degradation in the Lao PDR: Discourses and policy. Land Use Policy 27(2): 424-439.

Linquist, B., Trösch, K., Pandey, S., Phouynyavong, K., and Guenat, D. (2007). Montane Paddy Rice: Development and Effects on Food Security and Livelihood Activities of Highland Lao Farmers. Mountain Research and Development 27(1): 40-47.

LSUAFRP (2003). Report on the Diagnostic Survey in Namo District: Socioeconomics Component. Ministry of Agriculture and Forestry, National Agriculture and Forestry Research Institute, Lao Swedish Upland Agriculture and Forestry Research Programme, Vientiane.

Lu, D., Mausel, P., Brondizio, E., and Moran, E. (2004). Change detection techniques. International Journal of Remote Sensing 25(12): 2365-2407.

McGarigal, K., Cushman, S. A., Neel, M. C., and Ene, E. (2002). FRAGSTATS: Spatial Pattern Analysis Program for Categorical Maps. Computer software program produced by the authors at the 
University of Massachusetts, Amherst. Available at the following web site: www.umass.edu/landeco/research/fragstats/ fragstats.html.

Mertens, B., and Lambin, E. F. (2000). Land-Cover-Change Trajectories in Southern Cameroon. Annals of the Association of American Geographers 90(3): 467-494.

Mertz, O., Padoch, C., Fox, J., Cramb, R., Leisz, S., Lam, N., and Vien, T. (2009). Swidden Change in Southeast Asia: Understanding Causes and Consequences. Human Ecology 37(3): 259-264.

Messerli, P., Heinimann, A., and Epprecht, M. (2009). Finding Homogeneity in Heterogeneity-A New Approach to Quantifying Landscape Mosaics Developed for the Lao PDR. Human Ecology 37(3): 291-304.

Nowak, A., Southavilay, B., Souliyan, P., Bounmi, R., Ponepaseuth, I., Morel, N., Jullien, F., and Singkeuth, V. (2008). Participative Analysis of the Maize Supply Value Chain in Lao PDR. Ministry of Agriculture and Forestry (MAF), Programme of Capitalisation in Support of Rural Development Policy (PCADR), Central Unit (UC), Vientiane.

Padoch, C., Coffey, K., Mertz, O., Leisz, S. J., Fox, J., and Wadley, R. L. (2007). The Demise of Swidden in Southeast Asia? Local Realities and Regional Ambiguities. Danish Journal of Geography 107: 29-41.

Pan, X.-Z., Uchida, S., Liang, Y., Hirano, A., and Sun, B. (2010). Discriminating different landuse types by using multitemporal NDXI in a rice planting area. International Journal of Remote Sensing 31(3): 585-596.

Robichaud, W. G., Sinclair, A. R. E., Odarkor-Lanquaye, N., and Klinkenberg, B. (2009). Stable Forest Cover under Increasing Populations of Swidden Cultivators in Central Laos: the Roles of Intrinsic Culture and Extrinsic Wildlife Trade. Ecology and Society 14(1): 33 .

Roder, W. (2001). Slash-and-Bum Rice Systems in the Hills of Northern Lao PDR: Description. Challenges, and Opportunities. International Rice Research Institute (IRRI). Los Baños (Philippines).

Roder, W., Phengchanh, S., and Maniphone, S. (1997). Dynamics of soil and vegetation during crop and fallow period in slash-andburn fields of northern Laos. Geoderma 76(1-2): 131-144.

Ruthenberg, H. (1971). Farming systems in the tropics. Clarendon, Oxford.

Saito, K., Linquist, B., Keobualapha, B., Shiraiwa, T., and Horie, T. (2006). Farmers' knowledge of soils in relation to cropping practices: A case study of farmers in upland rice based slash-and-burn systems of northern Laos. Geoderma 136(1-2): 64-74.

Schmidt-Vogt, D., Leisz, S., Mertz, O., Heinimann, A., Thiha, T., Messerli, P., Epprecht, M., Cu, P., Chi, V., Hardiono, M., and
Dao, T. (2009). An Assessment of Trends in the Extent of Swidden in Southeast Asia. Human Ecology 37(3): 269-280.

Seidenberg, C., Mertz, O., and Kias, M. B. (2003). Fallow, labour and livelihood in shifting cultivation: implications for deforestation in northern Lao PDR. Geografisk Tidsskrift-Danish Journal of Geography 103(3): 10 .

Shi, W. (2008). Rubber boom in Luang Namtha a transnational perspective. GTZ (German Technical Cooperation). Vientiane, Lao PDR

Sordo, M., and Zeng, Q. (2005). On Sample Size and Classification Accuracy: A Performance Comparison. Biological and Medical Data Analysis. In Oliveira, J., Maojo, V., Martín-Sánchez, F., and Pereira, A. (eds.), Lecture Notes in Computer Science. Istrail, S., Pevzner, P. and Waterman, M. Springer, Berlin, pp. 193-201.

Sprenger, G. (2006). Out of the ashes: Swidden cultivation in highland Laos. Anthropology Today 22(4): 9-13.

Thongphanh, D., Yoshida, S., Mizoue, N., and Kajisa, T. (2011). Impact of Land Use and Land Cover Change on Local Livelihood in Pha-Oudom District, Bokeo Province, Lao PDR. National Agriculture and Forestry Research Institute, Vientiane.

van Noordwijk, M. (1999). Productivity of intensified crop-fallow rotations in the Trenbath model. Agroforestry Systems 47(1): 223-237.

Viau, J., Keophosay, A., and Castella, J.-C. (2009). Impact of maize expansion on traditional rice production systems in Northern Lao PDR. A case study in Xiengkhor district, Huaphan province. Catch-Up Programme, National Agriculture and Forestry Research Institute, Vientiane.

Wästfelt, A., Tegenu, T., Nielsen, M. M., and Malmberg, B. (2012). Qualitative satellite image analysis: Mapping spatial distribution of farming types in Ethiopia. Applied Geography 32(2): 465-476.

Watanabe, E., Sakurai, K., Okabayashi, Y., Lassay, N., and Alounsawat, C. (2004). Soil Fertility and Farming Systems in a Slash and Burn Cultivation Area of Northern Laos. Southeast Asian Studies 41(4): 519-537.

World Bank (2008). Policy, Market, and Agriculture Transition in the Northern Uplands. World Bank, Washington.

Yamamoto, Y., Oberthür, T., and Lefroy, R. (2009). Spatial identification by satellite imagery of the crop-fallow rotation cycle in northern Laos. Environment, Development and Sustainability 11 (3): 639-654.

Yokoyama, S. (2004). Forest, Ethnicity and Settlement in the Mountainous Area of Northern Laos. Southeast Asian Studies 42(2): 132-156.

Yokoyama, S., Tanaka, K., and Phalakhone, K. (2006). Forest Policy and Swidden Agriculture in Laos. SEAGA Conference, Singapore. 